\title{
ANALISIS PENDAPATAN DAN TINGKAT KESEJAHTERAAN RUMAH TANGGA PETANI SAYURAN DALAM PROGRAM TANGGUNG JAWAB SOSIAL PERUSAHAAN (Studi Kasus di Kelompok Tani Harapan Jaya Binaan PT Kaltim Prima Coal)

\author{
ANALYSIS OF INCOME AND WELFARE LEVEL OF VEGETABLE FARMER \\ HOUSEHOLDS IN THE SOCIAL RESPONSIBILITY PROGRAM (Case Study In
} Harapan Jaya Farmer Group Fostered By PT Kaltim Prima Coal)
}

\author{
Lathifaturrahmah*, Ahmad Choibar Tridakusumah
}

Program Studi Agribisnis, Fakultas Pertanian Universitas Padjadjaran

*Email: Lathifa.fatur@gmail.com

(Diterima 21-08-2020; Disetujui 01-11-2020)

\begin{abstract}
ABSTRAK
Perusahaan sebagai aktor pembangunan ekonomi nasional harus dapat berkontribusi bagi peningkatan kesejahteraan masyarakat serta lingkungan sekitarnya, bentuk kepedulian tersebut melalui program Tanggung Jawab Sosial Perusahaan/Corporate Social Responsibility (CSR), termasuk PT. Kaltim Prima Coal yang sudah menjalankan CSR Pengembangan Agribisnis sejak tahun 1999. Salah satu kelompok yang menjadi penerima manfaatnya adalah Kelompok Tani Harapan Jaya. Tujuan dari penelitian ini adalah (1) Mendeskripsikan penerapan CSR PT KPC pada kelompok tani Harapan Jaya, (2) Mengetahui struktur pendapatan dan pengeluaran rumah tangga petani sayuran anggota kelompok tani Harapan Jaya, dan (3) Mengetahui tingkat kesejahteraan rumah tangganya. Penelitian ini menggunakan desain kualitatif dengan metode studi kasus. Pemilihan tempat penelitian dilakukan secara sengaja (purposive) dengan pertimbangan bahwa daerah tersebut merupakan wilayah ring I yang paling dekat dengan kawasan tambang. Tingkat kesejahteraan rumah tangga diukur menggunakan garis kemiskinan Sayogyo (1996), World Bank, dan BPS. Hasil penelitian menunjukkan tingkat kesejahteraan rumah tangga petani berdasarkan kriteria Sayogyo (1996), World Bank dan BPS berturut-turut, 78,95\% rumah tangga petani tergolong ke dalam kategori tidak miskin, 57,89\% rumah tangga tergolong miskin dan 52,63\% rumah tangga petani tergolong ke dalam rumah tangga tidak miskin.
\end{abstract}

Kata kunci: Tanggung Jawab Sosial Perusahaan, Kesejahteraan, Rumah Tangga Petani.

\section{ABSTRACT}

Companies as national economic development actors must be able to contribute to improve the welfare of the community and the surrounding environment, this concern is proved by the Corporate Social Responsibility (CSR) program, including PT. Kaltim Prima Coal, which has implemented Social Responsibility for Agibusiness Development for farmers around the mine since 1999. One of the groups that becomes the beneficiary is Harapan Jaya Farmer Group. The purpose of this study is (1) Describe the application of Social Responsibility/CSR of PT. KPC in Harapan Jaya farmer group, (2) Find out the income and expenditure structure of vegetable farmer households who are members of Harapan Jaya farmer group, (3) Find out the welfare level of vegetable farmer households. This study uses a qualitative design with a case study method. The selection of study sites was carried out deliberately (purposive) with the consideration that the area is the ring I area closest to the mining area. The welfare level of household was measured using the poverty line of the Sayogyo (1996), World Bank, and BPS. The welfare level of farmers households based on Sayogyo's criteria (1996), World Bank and based on BPS poverty line criteria continued is criteria shows that $78.95 \%$ of farmer households are classified as not poor, $57.89 \%$ of households are classified as poor and $52.63 \%$ of farmer households are classified as poor.

Key words: Corporate Social Responsibility, Welfare, Farmer Households 


\section{PENDAHULUAN}

Kabupaten Kutai Timur memiliki potensi batubara yang sangat besar dengan hasil produksinya mencapai 82.530.414 juta ton di tahun 2017 (BPS Kabupaten Kutai Timur, 2019). Besarnya produksi batubara di Kabupaten Kutai Timur, menjadikan industri penggalian dan pertambangan sebagai tumpuan perekonomian di Kabupaten Kutai Timur. Sektor tersebut menjadi penyumbang tertinggi terhadap PDRB Kutai Timur tahun 2018, yakni sebesar 81,3 persen (BPS Kabupaten Kutai Timur, 2019).

Meskipun Kutai Timur memiliki sumber daya alam batubara yang melimpah, tetapi Kutai Timur tidak bisa selamanya menggantungkan perekonomiannya kepada industri batubara saja. Batubara adalah sumberdaya alam yang sifatnya tidak tergantikan dan persediaan batubara Indonesia akan habis pada tahun 2040 (Patriella, 2020). Maka dari itu, pembangunan di sektor lain juga perlu dilakukan supaya perekonomian Kabupaten Kutai Timur tetap hidup meski operasi tambang sudah tidak ada.

Salah satu sektor yang berpotensi untuk dikembangkan di Kabupaten Kutai Timur adalah Pertanian. Berdasarkan data BPS, pertanian menjadi sektor yang memberikan kontribusi tertinggi kedua terhadap PDRB Kab. Kutai Timur tahun 2018, sebesar 7,7\% (BPS Kab. Kutai Timur, 2019).

Subsektor pertanian mencakup hortikultura, tanaman pangan, perkebunan, peternakan, perikanan dan kehutanan. Di Kabupaten Kutai timur subsektor pertanian yang berpotensi di kembangkan adalah hortikultura. Produk hortikultura meliputi tanaman hias, tanaman obat, sayuran dan buah-buahan mempunyai peran penting bagi manusia dan lingkungan. Diantara produk hortikultura, sayuran memiliki manfaat yang besar bagi kehidupan manusia diantaranya sebagai sumber pangan dan gizi, pendapaan keluarga dan pendapatan negara (Ashari, 1995).

Potensi sayuran di Kabupetan Kutai Timur memperlihatkan prospek yang baik. Menurut BPS, produksi dan luas panen sayuran di Kalimantan Timur mengalami peningkatan pada tahun 2018. Peningkatan tersebut terjadi pada komoditas andalan Kab. Kutai Timur seperi bawang merah, cabai dan petsai. Rata-rata peningkatan produksi dan luas panen tahu 2018 berturut-turut 992,2 ton dan 15,75 hektar.

Peningkatan produksi dan luas panen mestinya akan berpengaruh pada kesejahteraan petani. Tetapi 
kenyataannya Nilai Tukar Pertani Hortikultura di Kalimantan Timur pada bulan Januari 2019 mengalami penurunan sebesar 0,61 persen menjadi 90,52 (BPS Kaltim, 2019).

Melihat belum sejahteranya petani hortikultura, maka perlu adanya peran serta perusahaan tambang di Kabupaten Kutai Timur dalam meningkatkan kesejehtaraan masyarakat sekitar operasinya termasuk petani Hortikultura. Secara tidak langsung, perusahaan tambang tersebut mengambil manfaat batubara di daerah Kutai Timur maka sudah menjadi timbal balik perusahaan untuk memberikan kontribusinya dalam mengembangan daerah serta masyarakat lokal guna menciptakan pembangunan berkelanjutan dan kemandirian masyarakat. Konsep tersebut dinamanakan tanggung jawab sosial perusahaan atau Corporate Social Responsibility (CSR).

PT. Kaltim Prima Coal adalah perusahaan tambang yang menjalankan CSR di bidang pertanian. CSR tersebut dituangkan dalam program "Pengembangan Agribisnis" dengan fokus program pengembangan budidaya tanaman pangan dan semusim. Kecamatan Bengalon dipilih sebagai tempat pelaksanaan program karena berada di wilayah ring I tambang. Salah satu kelompok yang menjadi binaan CSR PT. KPC adalah Kelompok Tani Harapan Jaya. Kelompok tani Harapan Jaya dipilih sebagai subjek penelitian karena kelompok tani ini adalah kelompok tani yang aktif dan rutin mendapat bantuan CSR PT. KPC. Kelompok tani Harapan Jaya mengusahakan tanaman sayur seperti kacang panjang, timun, tomat, cabai, bawang prey dan juga adalah buahbuahan semusim yakni semangka.

Maka dari itu peneliti tertarik untuk mengetahui penerapan tanggung jawab sosial PT KPC, struktur pendapatan dan pengeluaran rumah tangga, serta tingkat kesejehtaraan petani angota kelompok tani Harapan Jaya.

\section{METODE PENELITIAN}

Penelitian ini dilakukan di kelompok tani Harapan Jaya yang merupakan kelompok binaan PT KPC. Kelompok tani tersebut berlokasi di Desa Sepaso Barat, Kecamatan Bengalon, Kabupaten Kutai Timur. Pengumpulan data dilakukan pada bulan Februari 2020.

Desain penelitian yang digunakan adalah kualitatif dengan metode studi kasus. Sumber data utama dalam penelitian ini adalah data primer yang didapatkan langsung melalui pengamatan 
serta wawancara dengan informan dan reponden. Adapun data tambahan berupa data sekunder, diperoleh dari laporan tahunan serta data internal PT. Kaltim Prima Coal mengenai pelaksanaan tanggung jawab social.

Teknik pengumpulan data yang digunakan adalah Dokumentasi, wawancara, kuesioner dan observasi. Wawancara yang dilakukan pada penelitian ini adalah wawancara terstruktur. Wawancara dilakukan kepada responden dan informan penelitian. Informan penelitian berjumlah 4 dan dipilih secara purposif karena dianggap paling tahu tentang penerapan CSR PT KPC. Responden dalam penelitian ini adalah anggota kelompok tani harapan jaya yang berjumlah 19 orang. Adapun informan pada penelitian ini orang yang dapat dilihat pada Tabel 1.

Tabel 1. Informan Penelitian

\begin{tabular}{|c|c|c|}
\hline No & Nama & Jabatan \\
\hline 1 & Rujian NurMalik & $\begin{array}{l}\text { Officer Comm. Dev } \\
\text { BCRD PT KPC }\end{array}$ \\
\hline 2 & Khairul Anwar & $\begin{array}{l}\text { Ketua Kelompok } \\
\text { Tani Harapan Jaya }\end{array}$ \\
\hline 3 & Adi Mulyono & $\begin{array}{l}\text { PPL kelompok tani } \\
\text { Harapan Jaya }\end{array}$ \\
\hline 4 & M. Yunus & $\begin{array}{l}\text { Kasi. Pembangunan } \\
\text { Desa Sepaso Barat }\end{array}$ \\
\hline
\end{tabular}

Sumber: Data Primer, 2020

Teknik observasi yang dilakukan peneliti adalah partisipasi aktif, yang mana peneliti ikut turun ke lapangan dan melakukan apa yang narasumber kerjakan.

Metode analisis data yang digunakan dalam penelitian ini adalah analisis deskriptif untuk menggambarkan data yang telah terkumpul sebagaimana adanya. Analisis deskriptif pada penelitian ini bertujuan untuk mendeskripsikan penerapan CSR PT. KPC, menggambarkan karakteristik responden, dan tingkat kesejahteraan rumah tangga petani.

\section{Analisis Pendapatan Rumah Tangga Petani \\ Dalam penelitian ini, pendapatan} rumah tangga adalah pendapatan yang berasal dari pertanian dan non pertanian. Pendapatan rumah tangga menurut (Mubyarto, 1998) diartikan sebagai pendapatan yang diperoleh seluruh anggota keluarga, baik suami, istri, maupun anak. Adapun rumus pendapatan total rumah tangga petani adalah sebagai berikut:

$$
\text { TPRT }=\text { PS }+ \text { PI }+ \text { PL }
$$

Keterangan:

$$
\begin{array}{ll}
\text { TPRT } & =\text { Pendapatan rumah tangga } \\
\text { PS } & =\text { Pendapatan suami } \\
\text { PI } & =\text { Pendapatan istri } \\
\text { PL } & =\text { Pendapatan sumber lain }
\end{array}
$$




\section{Analisis Pengeluaran Rumah Tangga Petani}

Pengeluaran rumah tangga adalah biaya yang dikeluarkan untuk memenuhi kebutuhan hidup dalam jangka waktu satu tahun yang terdiri atas pengeluaran untuk makanan dan non makanan. Total pengeluaran rumah tangga didapatkan dalam rumus:

$$
K t=K 1+K 2
$$

Keterangan:

$\mathrm{Kt} \quad=$ Pengeluaran Total

$\mathrm{K} 1$ = Pengeluaran untuk makanan

K2 = Pengeluaran untuk non makanan

\section{Analisis Kesejahteraan Rumah Tangga}

\section{Petani}

Tingkat kesejahteraan rumah tangga petani pada penelitian ini menggunakan kriteria garis kemiskinan Sajogyo, yang dikutip oleh Soemarwoto (1991), World Bank dan BPS. Adapun kriteria garis kemiskinan dijelaskan pada uraian di bawah ini:

\section{Sayogyo (1997)}

Tingkat kemiskinan didasarkan dengan jumlah rupiah pengeluaran rumah tangga yang disetarakan dengan jumlah kilogram konsumsi beras per orang per tahun. Harga beras rata-rata di lokasi

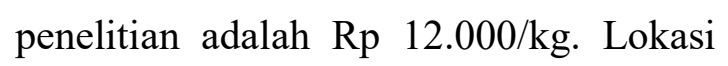
penelitian adalah lingkungan pedesaan, maka kriteria kemiskinan digolongkan ke dalam tiga bagian:

1. Tidak miskin, yaitu apabila pendapatan per kapita per tahun lebih tinggi dari nilai tukar $320 \mathrm{~kg}$ beras.

2. Miskin, yaitu apabila pendapatan per kapita per tahun lebih kecil dari nilai tukar $320 \mathrm{~kg}$ beras.

3. Miskin Sekali, yaitu apabila pendapatan per kapita per tahun lebih kecil dari nilai tukar $240 \mathrm{~kg}$ beras.

4. Paling Miskin, yaitu apabila pendapatan per kapita per tahun lebih kecil dari nilai tukar $180 \mathrm{~kg}$ beras.

\section{Garis Kemiskinan World Bank} (2020)

Dalam World Bank (2020), Garis kemiskinan saat ini adalah US\$ 1,9 per hari. Dikatakan masyarakat miskin apabila konsumsi per kapita per harinya di bawah US\$ 1,9; dan dikatakan tidak miskin jika konsumsi per kapita per harinya di atas garis kemiskinan tersebut.

\section{Garis Kemiskinan BPS}

Untuk mengukur kemiskinan, BPS menggunakan konsep kemampuan memenuhi kebutuhan dasar (Basic Needs Approach). Penduduk miskin adalah penduduk yang memiliki rata-rata pengeluaran per kapita per bulan di bawah garis kemiskinan. Garis kemiskinan Kalimantan Timur per Maret 
2020 adalah Rp 665.970 per kapita/bulan di perkotaan, dan $\mathrm{Rp} 652.620$ per kapita/bulan di pedesaan (Badan Pusat Statistik Kalimantan Timur, 2020).

\section{HASIL DAN PEMBAHASAN}

\section{Karakteristis Petani sayuran anggota} kelompok tani Harapan Jaya

Mayoritas petani berada pada usia produktif yakni 41-50 tahun. Berdasarkan pendidikan terakhir, kebanyakan petani merupakan tamatan SD. Hampir semua petani menjadikan bertani sayur sebagai pata pencaharian utama. Berdasarkan pengalaman berusahatani, mayoritas memiliki pengelaman selama 6-10 tahun. Berdasarkan status lahan, hampir seluruh petani mengusahakan lahan pinjaman. Berdasarkan luas lahan, mayoritas petani memiliki lahan yang sedang, yakni luasnya 0,5-2 hektar. Sedangkan berdasarkan jumlah tanggungan rumah tangga, mayoritas jumlah tanggungannya 3-4 orang.

\section{Penerapan Program CSR PT KPC}

PT KPC adalah perusahaan pertambangan batubara yang memegang perjanjian PKP2B, dan mengelola salah satu pertambangan open-pit terbesar di dunia. Perusahaan ini berlokasi di
Sangatta, Kab. Kutai Timut, Kalimantan Timur.

Dalam penerapan CSR, PT KPC membentuk tujuh bidang program pembangunan, yakni Pengembangan Agribisnis, Pengembangan Ekonomi Lokal dan UKM, Kesehatan dan Sanitasi, Pendidikan dan Pelatihan, Peningkatan insfrastruktur, peningkatan kapasitas Pemerintah Desa dan Masyarakat serta Konservasi Alam dan Budaya.

Pengembangan Agribisnis adalah program yang dijalankan dalam rangka mendukung agenda pembangunan Pemerintah Daerah Kutai Timur di bidang agribisnis dan agroindustri. Program ini merupakan program di bidang ekonomi yang bertujuan untuk menumbuhkan perekonomian lokal di bidang pertanian dengan memberikan bantuan seperti pelatihan, pendampingan, stimulan kepada masyarakat, serta mendorong terbentuknya tataniaga yang baik di bidang usaha agribisnis dan meningkatkan produktifitas masyarakat. Salah satu fokus programnya adalah pengembangan budidaya tanaman pangan dan tanaman semusim. Program ini dikhususkan bagi kelompok tani di Kec. Bengalon dan salah satunya adalah kelompok tani Harapan Jaya. Dikhususkan untuk kelompok tani di 
Bengalon, karena Kecamatan Bengalon merupakan kawasan Ring 1 (kawasan yang paling terdekat dengan tambang), dan memiliki potensi pertanian yang baik. Untuk bisa menjadi kelompok binaannya, terdapat beberapa proses dan tahapan, yakni pertama kelompok harus mengajukan proposal bantuan ke PT KPC, selanjutnya perusahaan akan melakukan seleksi administrasi, jika dikatakan lolos maka selanjutnya PT. KPC akan melakukan penilaian atau justifikasi lapangan untuk melihat apakah bantuan yang diajukan tepat sasaran, selanjutnya jika dinilai tepat maka PT KPC akan melakukan serah terima bantuan, dan selanjutnya kelompok tersebut akan diberi pendampingan, monotoring rutin. Selanjutnya akan dilakukan evaluasi dengan melihat sejauh apa perkembangan kelompok setelah diberi bantuan CSR, apabila perkembangan kelomok baik, maka dari PT KPC akan menyiapkan bantuan selanjutnya.

Kelompok tani Harapan Jaya sudah mendapatkan bantuan CSR sejak tahun 2011. Bantuan yang telah diterima kelompok tani ini terbagi menjadi dua, yakni bantuan fisik dan bantuan nonfisik. Bantuan fisik berupa sarana produksi dan mesin pertanian seperti:
Sapi 11 ekor, bibit jagung hibrida, sumur bor, Biogas, Alchon, Selang dan Cultivator. adapun bantuan non fisiknya berupa, pelatihan, pendampingan dan monitoring.

\section{Struktur Pendapatan Rumah Tangga Petani}

Struktur pendapatan rumah tangga petani dibagi menjadi dua kelompok yaitu pendapatan dari sektor pertanian dan non pertanian. Sumber pendapatan sektor pertanian berasal dari usahatani sayuran, usahatani non sayuran, sawit, ternak dan buruh (off farm). Adapun sumber pendapatan non pertanian berasal dari tukang bangunan, aparatur desa, pedagang, wiraswasta dan penyedia jasa. Adapun pendapatan total rumah tangga berasal dari pendapatan seluruh anggota keluarga, yakni suami, istri, anak dan anggota lainnya.

Tabel 2. Pendapatan Rumah Tangga Petani (Rata-rata/tahun)

\begin{tabular}{lccccc}
\multicolumn{7}{c}{ (Rata-rata/tahun) } \\
\multirow{2}{*}{ Uraian } & On & Off & Non & \multirow{2}{*}{ Total } & $\%$ \\
& farm & farm & Farm & & \\
\hline Suami & 47.980 & 29 & 5.413 & 53.422 & 81 \\
Istri & 1.849 & 95 & 1.489 & 3.433 & 5 \\
Anak & - & - & 9.347 & 9.347 & 14 \\
Lainnya & - & - & 26 & 26 & 0 \\
\hline \multicolumn{7}{l}{ Total (Rp/Tahun) } & & & 66.229 & 100 \\
\hline
\end{tabular}

Sumber: Data Primer, 2020

$$
\text { Pada Tabel } 2 \text { dapat dilihat }
$$
bahwasanya kontribusi tertinggi pendapatan rumah tangga berasal dari suami atau kepala keluarga, yakni 81\%. 


\section{ANALISIS PENDAPATAN DAN TINGKAT KESEJAHTERAAN RUMAH TANGGA PETANI SAYURAN \\ DALAM PROGRAM TANGGUNG JAWAB SOSIAL PERUSAHAAN \\ Lathifaturrahmah, Ahmad Choibar Tridakusumah}

Hal ini menunjukkan bahwa peran suami atau kepala keluarga sangat besar terhadap pendapatan rumah tangga. Selain itu, rata-rata pendapatan tertinggi suami berasal dari on farm, yang menandakan bahwasanya bertani merupakan mata pencaharian utama rumah tangga petani. Adapun kontribusi tertinggi kedua berasal dari pendapatan anak (14\%) yang mana rata-rata anak petani bekerja di sektor non pertanian khususnya pada perusahaan pertambangan. Kontribusi istri terhadap pendapatan rumah tangga menyumbang sebesar 5,18\%. Rata-rata istri bekerja sebagai pedagang warung sembako dan berusaha tani. Kontribusi pendapatan istri tidak tinggi karena bukan menjadi sumber utama pendapatan dan hanya sebagai tambahan pendapatan rumah tangga saja.

\section{Struktur Pengeluaran Rumah Tangga}

Petani

Pada penelitian ini pengeluaran rumah tangga petani dibedakan menjadi dua, yaitu pengeluaran untuk pangan dan pengeluaran untuk non pangan.

Pengeluaran pangan pada penelitian ini dibagi menjadi pengeluaran sumber karbohidrat (beras), pangan hewani (daging, ikan dan telur), pangan nabati (tahu, tempe), sayuran, buah-buahan, minyak, mie instan, bahan minuman (teh, kopi dan gula) dan tembakau atau rokok. Sedangkan pengeluaran non pangan dibagi menjadi pengeluaran atas biaya kesehatan, biaya pendidikan, biaya sandang (pakaian, peralatan mandi), biaya sosial (rekreasi, hubungan sosial), bahan bakar (listrik, bensin, gas), pemeliharaan tempat tinggal, biaya pulsa dan kuota internet dan biaya non pangan lainnya. Adapun pengeluaran rumah tangga petani dapat dilihat pada Tabel 3 .

Tabel 3. Pengeluaran Rumah Tangga Petani (Rata-rata/bulan)

\begin{tabular}{|c|c|c|}
\hline Jenis Pengeluaran & $\begin{array}{c}\text { Rata-rata } \\
\text { Pengeluaran per } \\
\text { Bulan (Rp) } \\
\end{array}$ & $(\%)$ \\
\hline \multicolumn{3}{|l|}{ Pangan } \\
\hline -Beras & 515.294 & 21,79 \\
\hline -Rokok & 510.625 & 21,59 \\
\hline -Daging Sapi & 151.111 & 6,39 \\
\hline -Ikan & 371.000 & 15,69 \\
\hline -Telur Ayam & 125.333 & 5,30 \\
\hline -Gula Pasir & 77.667 & 3,28 \\
\hline -Mie Instan & 71.214 & 3,01 \\
\hline -Kopi/teh & 36.500 & 1,54 \\
\hline -Sayuran & 141.429 & 5,98 \\
\hline -Buah-Buahan & 65.000 & 2,75 \\
\hline -Tahu & 126.375 & 5,34 \\
\hline -Tempe & 106.867 & 4,52 \\
\hline -Minyak & 66.389 & 2,81 \\
\hline Total & 2.364 .804 & 100 \\
\hline \multicolumn{3}{|l|}{ Non-Pangan } \\
\hline -Pakaian & 228.000 & 6 \\
\hline -Perlengkapan Mandi & 87.706 & 2,15 \\
\hline -Bensin & 374.512 & 9,20 \\
\hline -Listrik & 234.016 & 5,75 \\
\hline -Gas/kayu bakar & 123.846 & 3,04 \\
\hline -Pulsa dan kuota & 123.765 & 3,04 \\
\hline -Pendidikan & 1.432 .455 & 35,17 \\
\hline -Kesehatan & 126.250 & 3,10 \\
\hline $\begin{array}{l}\text {-Pemeliharan tempat } \\
\text { tinggal }\end{array}$ & 516.000 & 12,69 \\
\hline -Rekreasi & 300.000 & 7,37 \\
\hline -Hubungan sosial & 166.667 & 2,86 \\
\hline $\begin{array}{l}\text {-Bukan Makanan } \\
\text { Lainnya }\end{array}$ & 409.000 & 10,04 \\
\hline Total & 4.072 .882 & 100 \\
\hline
\end{tabular}

Sumber: Data Primer, 2020 
Alokasi terbesar untuk pengeluaran pangan digunakan untuk membeli beras, yakni Rp 515.294/bulan atau 21,79 dari total pengeluaran pangan rumah tangga. Hal ini menandakan bahwa sebagian besar petani anggota mengkonsumsi beras sebagai sumber karbohidrat. Sedangkan pengeluaran rumah tangga non pangan terbesar digunakan untuk biaya pendidikan, yakni $\mathrm{Rp}$ $1.432 .455 /$ bulan atau 35,17 persen dari total pengeluaran non pangan. Hal ini menandakan bahwasanya rumah tangga petani sangat peduli akan pendidikan anaknya.

Tabel 4. Presentase pengeluaran pangan dan non pangan rumah tangga petani

\begin{tabular}{lcc}
\hline $\begin{array}{c}\text { Jenis } \\
\text { Pengeluaran }\end{array}$ & $\begin{array}{c}\text { Pengeluaran Rata- } \\
\text { rata per Tahun } \\
(\mathrm{Rp})\end{array}$ & $\begin{array}{c}\text { Persentase } \\
(\%)\end{array}$ \\
\hline Pangan & 23.648 .036 & 36,7 \\
Non Pangan & 40.728 .824 & 63,3 \\
\hline Total & 64.376 .860 & 100,00
\end{tabular}

Sumber: Data Primer, 2020

Jika dilihat dari rata-rata pengeluaran rumah tangga petani secara umum, pengeluaran untuk non pangan lebih besar dibanding pengeluaran untuk pangan. Rata-rata pengeluaran non pangan mencapai Rp 40.728.824 per tahun atau 63,3 persen dari total keseluruhan pengeluaran rumah tangga, sedangkan pengeluaran pangan mencapai Rp 23.648.036 per tahun atau 36,7 persen dari keseluruhan total pengeluaran rumah tangga petani. Dapat disimpulkan bahwa rata-rata rumah tangga petani memiliki ketahan pangan yang tinggi.

Tingkat Kesejahteraan Rumah Tangga Petani

Pada penelitian ini tingkat kesejahteraan rumah tangga petani dilihat menggunakan Kriteria Sajogyo (1997), World Bank, BPS.

\section{Kriteria Sajogyo (1997)}

Kriteria ini menggunakan beras sebagai dasar penggolongan tingkat kemiskinan yang dibandingkan dengan pendapatan per kapita per tahun. Tingkat kesejahteraan rumah tangga petani sayuran anggota kelompok tani Harapan Jaya dapat dilihat pada Tabel 5.

Tabel 5. Kriteria Tingkat kesejahteraan Rumah Tangga Petani Berdasarkan Kemiskinan Sayogyo (1997)

\begin{tabular}{lcc}
\hline Kriteria & Jumlah & $\%$ \\
\hline $\begin{array}{l}\text { Tidak Miskin } \\
\text { (Pendapatan/kapita/tahun }\end{array}$ & 15 & 78,95 \\
$\geq 4.320 .000)$ & & \\
$\begin{array}{l}\text { Miskin } \\
\text { (Pendapatan/kapita/tahun }\end{array}$ & 1 & 5,26 \\
$\begin{array}{l}\text { 2.880.000 - 4.308.000) } \\
\text { Miskin sekali } \\
\text { (Pendapatan/kapita/tahun }\end{array}$ & 0 & 0,00 \\
$\begin{array}{l}2.160 .000-2.868 .000) \\
\text { Paling miskin } \\
\text { (Pendapatan/kapita/tahun }\end{array}$ & 3 & 15,79 \\
$<2.160 .000)$ & & \\
\hline Total & & \\
\hline Sumber: Data Primer, & & \\
\hline & 19 & 100 \\
\hline
\end{tabular}

Sumber: Data Primer, 2020

Berdasarkan konsep kriteria Sajogyo (1997), mayoritas rumah tangga petani berada di atas garis kemiskinan 
dan masuk ke dalam kriteria tidak miskin $(78,95 \%)$. Sedangkan sisanya yakni 4 rumah tangga berada di bawah garis kemiskinan. Sebanyak $15,79 \%$ rumah tangga petani masuk ke dalam kriteria paling miskin dan 5,26\% rumah tangga petani masuk ke dalam kriteria miskin.

\section{Kriteria Garis Kemiskinan World Bank}

Dalam World Bank (2020), Garis kemiskinan ekstrim dirubah pada Oktober 2011 menjadi US\$ 1,9 komsumsi per hari. Per Agustus 2020, nilai 1,9 dollar Amerika Serikat setara dengan Rp 28.104,80. Jika konsumsi per kapita per hari rumah tangga petani dibawah $\mathrm{Rp} 28.104,80$, maka rumah tangga tersebut digolongkan dalam keluarga miskin. Tingkat kemiskinan rumah tangga petani berdasarkan kriteria World Bank dapat dilihat pada Tabel 6.

Tabel 6. Kriteria Tingkat Kesejahteraan Rumah Tangga Petani Berdasarkan Garis Kemiskinan World Bank

\begin{tabular}{lcc}
\hline \multicolumn{1}{c}{ Kategori } & Jumlah & $\%$ \\
\hline $\begin{array}{l}\text { Tidak Miskin } \\
\text { (Pengeluaran/kapita/hari }\end{array}$ & 8 & 42,11 \\
$\geq$ Rp 28.104,80) & & \\
$\begin{array}{l}\text { Miskin } \\
\text { (Pengeluaran/kapita/ } \\
\text { hari }<\text { Rp 28.104,80) }\end{array}$ & 11 & 57,89 \\
\hline \multicolumn{1}{c}{ Total } & 19 & 100,00 \\
\hline
\end{tabular}

Sumber: Data Primer, 2020

Berdasarkan Tabel 6, diketahui bahwasanya mayoritas rumah tangga petani yakni $57,89 \%$, masuk ke dalam kriteria miskin. Rata-rata pengeluaran per kapita per hari rumah tangga miskin Rp 18.067. Sisanya, 42,11\% rumah tangga petani sayuran yang masuk ke dalam ketegori tidak miskin dengan rata-rata pengeluaran per kapita per hari Rp 39.115 .

\section{Kriteria Garis Kemiskinan BPS}

Berdasarkan BPS, penduduk miskin adalah yang memiliki pengeluaran per kapita per bulan di bawah garis kemiskinan. Pada penelitian ini, garis kemiskinan yang digunakan adalah garis kemiskinan provinsi Kalimantan Timur di daerah pedesaan per bulan Maret 2020, yakni sebesar Rp 652.620. Kriteria kesejahteraan rumah tangga petani berdasarkan garis kemiskinan BPS dapat dilihat pada Tabel 7.

Tabel 7. Kriteria Tingkat Kesejahteraan Rumah Tangga Patani Berdasarkan Garis Kemiskinan BPS

\begin{tabular}{lcc}
\hline \multicolumn{1}{c}{ Kategori } & Jumlah & $\%$ \\
\hline $\begin{array}{l}\text { Tidak Miskin } \\
\text { (Pengeluaran/kapita/bulan }\end{array}$ & 10 & 52,63 \\
$\geq$ Rp 652.620) & & \\
$\begin{array}{l}\text { Miskin } \\
\text { (Pengeluaran/kapita/bulan }\end{array}$ & 9 & 47,37 \\
$<$ Rp 652.620) & & \\
\hline Total & 19 & 100,00 \\
\hline Sumber: Data Primer, 2020 & &
\end{tabular}

Bersadarkan kriteria tersebut, sebanyak $10 \quad(52,63 \%)$ rumah tangga petani masuk ke dalam kategori tidak miskin, rata-rata pengeluaran per kapita 
per bulannya adalah Rp 499.717. Adapun sebanyak 47,37 persen atau 9 rumah tangga petani anggota Kelompok Tani Harapan Jaya yang masuk ke dalam kategori Miskin dengan rata-rata pengeluaran per kapita per bulannya adalah Rp 1.085.211.

\section{Kriteria Rumah Layak BPS (2018)}

Menurut BPS (2018), rumah layak huni ditinjau dari beberapa kriteria, yakni 1) Ketahanan bangunan seperti bahan bangunan atap, dinding dan lantai rumah yang memenuhi syarat, 2) luas laintai minimal 7,2 meter persegi per kapita, 3) memiliki sumber penerangan utama listrik, 4) mempunyai akses air minum layak, dan 5) memiliki akses sanitasi yang layak. Rumah tangga dikatakan layak jika terdapat maksimum dua kriteria yang tidak terpenuhi dari tujuh indikator pembentukan. Adapun kelayakan huni rumah petani dapat dilihat pada Tabel 8 .

Tabel 8. Kriteria Hunian Rumah Tangga

\begin{tabular}{lcc}
\multicolumn{1}{c}{ Petani } & & \\
\hline Kriteria & Jumlah & $\%$ \\
\hline Layak & 18 & 94,7 \\
Tidak Layak & 1 & 5,3 \\
\hline Total & 19 & 100,0 \\
\hline
\end{tabular}

Sumber: Data Primer, 2020

Bersadarkan Tabel 8, diperoleh hasil bahwasanya tempat tinggal rumah tangga petani sebagian besar masuk ke dalam kategori layak huni yakni sebesar
94,7 persen, dan hanya sebagian kecil, yakni 5,3 persen yang tidak sesuai dengan kategori rumah layak huni.

\section{Gabungan Indikator Kesejahteraan}

Untuk mengetahui tingkat kesejahteraan rumah tangga petani anggota kelompok secara umum, maka dilihat dengan menggabungan kriteria kermiskinan menurut tiga metode, yakni Garis kemiskinan Sajogyo (berdasarkan pendapatan per kapita per tahun), Garis kemiskinan World Bank (berdasarkan pengeluaran per kapita per hari) dan Kondisi tempat tinggal petani berdasarkan BPS (2018).

Kategori kesejahteraan tersebut dibagi menjadi tiga, yakni 1) Benarbenar miskin jika dikatakan miskin oleh dua kategori dan memiliki rumah tidak layak huni, 2) Miskin, jika tergolong miskin oleh dua kategori atau salah satu kategori dan memiliki rumah tidak layak. 3) Tidak Miskin, jika tergolong miskin oleh salah satu kategori, atau tidak tergolong miskin oleh dua kateori tetapi memiliki rumah yang tidak layak dan 4) Benar-benar Tidak Miskin, jika tidak tergolong miskin oleh dua kategori dan memiliki rumah yang layak (Tabel 9).

Berdasarkan Tabel 9, diketahui bahwasanya mayoritas rumah tangga petani tergolong dalam kategori rumah 
tangga tidak miskin, yakni sebanyak 8 rumah tangga atau 42,11 persen. Sebanyak 7 rumah tangga atau 36,84 persen masuk ke dalam kategori benarbenar tidak miskin dan sebanyak 4 rumah tangga atau 21,05 persen tergolong ke dalam rumah tangga miskin.

Tabel 9. Gabungan Indikator Kesejahteraan

\begin{tabular}{lcc}
\hline Kriteria & Jumlah & $\%$ \\
\hline Benar-Benar miskin & 0 & 0 \\
Miskin & 4 & 21,05 \\
Tidak miskin & 8 & 42,11 \\
Benar-benar tidak miskin & 7 & 36,84 \\
\hline Total & 19 & 100 \\
\hline
\end{tabular}

Sumber: Data Primer, 2020

Berdasarkan keadaan di lapangan, rumah tangga petani miskin adalah mereka yang memiliki luas lahan ratarata 0,44 dan berdasarkan Hertanto (2018) masuk ke dalam kategori lahan sempit. Adapun rata-rata jumlah tanggungan rumah tangga 7 orang dan masuk ke dalam kategori keluarga besar menurut BKKBN (1994). Jumlah tanggungan keluarga akan mempengaruhi pendapatan per kapita rumah tangga, semakin banyak tanggungannya, maka pendapatan per kapitanya akan semakin kecil. Selain itu, rumah tangga miskin adalah mereka yang memperoleh penerimaan di bawah rata-rata $(\mathrm{Rp}$ 61.413.00) penerimaan petani poktan Harapan Jaya. Rata-rata penerimaan rumah tangga miskin dari usahatani $\mathrm{Rp}$ 14.467.750.

Jika dikaitkan antara rumah tangga miskin dengan bantuan CSR PT. KPC, hanya 2 rumah tangga yang menggunakat alat CSR seperti alkon dan cultivator, 2 lainnya mengaku tidak pernah menggunakan bantuan tersebut. Selain itu, salah satu petani yang tidak menggunakan alat CSR, mengaku kesulitan dalam penyiraman tanaman pada saat kemarau, karena sumber air terdekat mengering, sehingga air di sumber lain hanya bisa dijangkau jika menggunakan alkon.

\section{KESIMPULAN DAN SARAN}

\section{Kesimpulan}

1. Program Pengembangan Agribisnis adalah program Tanggung Jawab Sosial PT. Kaltim Prima Coal di bidang ekonomi yang bertujuan untuk menciptakan dan mengembangkan kegiatan agribisnis berdasarkan potensi lokal pertanian. Salah satu fokus programnya adalah pengembangan budidaya tanaman pangan dan musim. Bentuk kegiatannya berupa pemberian pelatihan, pendampingan dan stimulan kepada masyarakat khususnya petani. Kelompok Tani 
Harapan Jaya adalah salah satu kelompok binaan PT. KPC yang telah menerima bantuan sejak awal kelompok tani ini terbentuk yakni pada tahun 2011 hingga 2020. Adapun bantuan yang telah diterima Kelompok Tani Harapan Jaya adalah pendampingan, pelatihan, bibit hibrida jagung alchon, sumur bor, tandon, selang, dan cultivator.

2. Pendapatan rumah tangga petani dari pendapatan suami memberikan kontribusi tertinggi, yakni sebesar $80,66 \%$ dari total pendapatan per tahun rumah tangga, yakni sebesar (rata-rata) $\quad \mathrm{Rp} \quad 53.4222 .086$. Pengeluaran rumah tangga petani terbesar berasal dari pengeluaran non pangan, yakni sebesar 63,3\%, dan untuk pangan sebesar 36,7\%. Pengeluaran non pangan yang lebih besar dari pangan menandakan bahwa rumah tangga petani mayoritas memiliki ketahan pangan yang tinggi.

3. Berdasarkan kriteria Sayogyo (1997), mayoritas rumah tangga petani, yakni $78,95 \%$ masuk dalam kriteria tidak miskin. Berdasarkan World Bank, $57,89 \%$ rumah tangga petani tergolong dalam kategori miskin dan berdasarkan Garis Kemiskinan BPS $52,63 \%$ rumah tangga tergolong tidak miskin. cukup sejahtera, 26,32\% tergolong hidup layak, 15,79\% Miskin sekali. Berdasarkan kriteria rumah layak huni BPS (2018), mayoritas rumah tangga yakni sebesar 94,7\%. Jika menggabungkan tiga indikator (Sajogyo, World Bank dan kriteria rumah layak huni), mayoritas rumah tangga petani tergolong dalam kategori rumah tangga tidak miskin, yakni 42,11 persen.

\section{Saran}

1. Bagi pihak penyelenggara CSR, yakni PT. KPC diharapkan mampu melakukan evaluasi atas barang bantuan yang diberikan kepada kelompok, karena pemanfaatannya tidak dirasakan merata oleh anggota. Selain itu, PT KPC diharapkan kedepannya mampu memberikan bantuan yang sesuai dengan kebutuhan binaanya. Salah satu kebutuhan petani kelompok tani Harapa Jaya adalah bantuan mesin alcon dan pupuk.

2. Bagi petani, supaya bisa memanfaatkan bantuan yang telah diberikan PT KPC dengan sebaik mungkin. Selain itu petani diharapkan mulai melakukan pencatatan usahatainya agar dapat mengetahui 
efektifitas dan efisiensi dari usahatani yang dijalankannya.

3. Bagi kelompok, diharapkan melakukan penjadwalan pemakaian mesin bantuan CSR, supaya bisa dimanfaatkan oleh seluruh anggota. Selain itu, diharapkan kelompok menyusun penjadwalan waktu tanam antar petani yang menanam komoditas serupa, supaya tidak terjadi panen secara bersamaan, karena hal tersebut mampu menurunkan harga komoditas tersebut.

4. Bagi pemerintah, diharapkan mampu untuk terus memperhatikan kebutuhan petani salah satunya adalah dengan menyediakan pupuk bersubsidi.

\section{DAFTAR PUSTAKA}

Ashari, S. (1995). Hortikultura Aspek Budidaya. Jakarta: UI Press.

Badan Pusat Statistik. (2018, November 28). Indikator Kesejahteraan Rakyak 2018; Hunian Layak Masyarakat Berpenghasilan Rendah. Retrieved from www.bps.go.id: www.bps.go.id: https://www.bps.go.id/publication/2 018/11/28/f6adb407ea72d9b66776a 270/indikator-kesejahteraan-rakyat2018.html

Badan Pusat Statistik Kab. Kutai Timur . (2019, 8 16). Kabupaten Kutai Timur Dalam Angka 2019. Retrieved from https://kutimkab.bps.go.id/: https://kutimkab.bps.go.id/publicati on/2019/08/16/8c774b0d165b1712 6d48f537/kabupaten-kutai-timurdalam-angka-2019.html

Badan Pusat Statistik Kalimantan Timur. (2019). Berita Resmi Satistik; Perkembangan Nilai Tukar Petani (NTP) Kalimantan Timur Menurut Subsektor Bulan September 2019. Samarinda: Badan Pusat Satistik .

Badan Pusat Statistik Kalimantan Timur. (2020, 7 15). Maret 2020: Persentase Penduduk Miskin di Kalimantan Timur sebesar 6,10 persen. Retrieved from https://kaltim.bps.go.id/:

https://kaltim.bps.go.id/pressrelease/20 20/07/15/790/maret-2020--persentasependuduk-miskin-di-kalimantan-timursebesar-6-10-persen.html

Hertanto, F. (2018). Ilmu Usahatani. Jakarta: Penebar Swadaya.

Patriella, Y. (2020, Januari 22). Cadangan Batu Bara di Prediksi Habis 20 Tahun Lagi, Ini Alasannya! Retrieved from Bisnis.com:

https://m.bisnis.com/amp/read/2020 0122/44/1192993/cadangan-batubara-diprediksi-habis-20-tahunlagi-ini-alasannya

Sajogyo. (1997). Garis Kemiskinan dan Kebutuhan Minimum Pangan. Bogor: LPSP-IPB.

Soemarwoto, O. (1991). Ekologo Dalam Pembangunan Bewawasan Lingkungan. Makalah Dalam Rangka Penghormatan Purnabakti Prof. Otto Soemarwoto. Bandung: Universitas Padjadjaran.

World Bank. (2020, Agustus). Meta Data. Retrieved from https://databank.worldbank.org: https://databank.worldbank.org/Vie ws/Metadata/MetadataWidget.aspx ?Name $=$ Number $\% 20$ of $\% 20$ poor $\% 2$ 0at $\% 20 \$ 1.90 \% 20 \mathrm{a} \% 20$ day $\% 20(20$ 11\%20PPP) $\% 20$ (millions) $\&$ Code $=$ SI.POV.NOP1\&Type=S\&ReqType $=$ Metadata $\& d d 1$ SelectedValue $=\& \mathrm{R}$ eportID $=2626 \&$ ReportType $=$ Chart 